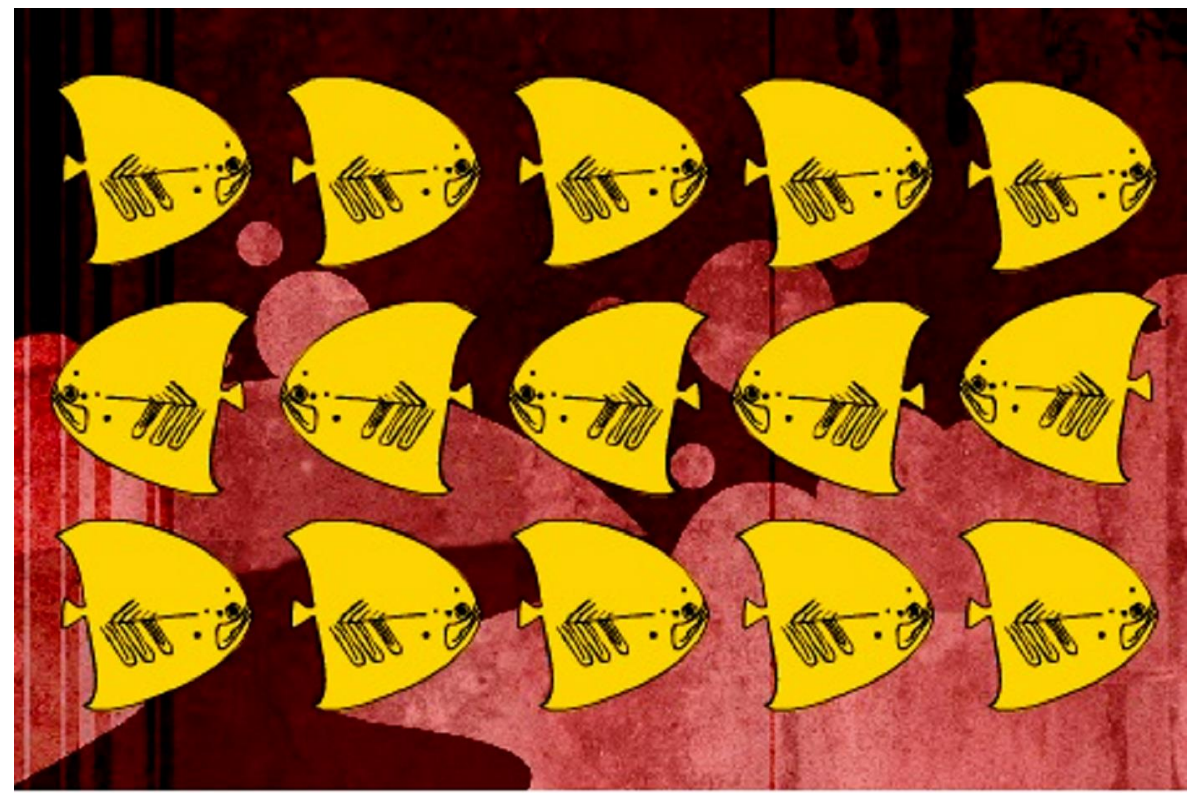

Rubens Rangel

\title{
Do fragmento às novas subjetividades - entrevista com o Núcleo de Psicanálise e Práticas Institucionais
}

\section{Por Maria Antonieta Pereira}

Raquel Corrêa Ferreira é psicóloga, psicanalista, esquizoanalista e analista institucional. Fundadora do Núcleo de Psicanálise e Práticas Institucionais - NPPI. Professora e supervisora do NPPI.

Ângela Carneiro Ricardo é psicóloga, psicanalista, esquizoanalista e analista institucional. Membro da coordenação geral do NPPI.

João Lúcio Dias Soares é psicanalista, esquizoanalista, acupunturista, comunicólogo. Professor e coordenador do setor de formação do NPPI. Membro da coordenação geral do NPPI.

Maria Antonieta Pereira é professora aposentada de Teoria da Literatura e Literatura Comparada na Faculdade de Letras/UFMG, onde atualmente exerce trabalho voluntário na Graduação e na Pós-Graduação. Pós-doutora pela Universidad de Buenos Aires. Pesquisadora convidada pela "Canada Research Chair in Literay 
and Cultural Transfers", Universidade de Ottawa, Canadá. Autora de vários livros e artigos sobre telas, textos e educação. Pesquisa atual: Esquecer para lembrar - redes narrativas na cibercultura. Fundadora do Programa de Ensino, Pesquisa e Extensão A tela e o texto e membro de sua Coordenação Geral.

A entrevista a seguir foi realizada com os psicanalistas Raquel Corrêa Ferreira, Ângela Carneiro Ricardo e João Lúcio Dias Soares, na qualidade de membros do NPPI. Os entrevistados responderam de forma individual ou coletiva às perguntas.

Maria Antonieta Pereira/Revista txt - Quando e com quais objetivos foi fundado $o$ Núcleo de Psicanálise e Práticas Institucionais?

Raquel Corrêa - Em 1972, o Núcleo foi criado com o nome de Núcleo de Psicanálise e Psicoterapia, com a proposta de atender/estudar uma ampla área de problemáticas - tanto as consideradas típicas da psicanálise, quanto as que extrapolam esse campo, aqueles casos cujo aparelho psíquico é mais primitivo, e que demandam um tipo de atendimento a partir de autores que enfocam o pré-genital. Esses casos teriam que ser primeiramente preparados, para experimentarem uma futura análise tipicamente psicanalítica. Outra novidade do Núcleo era prestar atendimento a famílias e casais, numa época em que - atendimento psicanalítico era realizado somente de forma individual. Aos poucos, a proposta foi se estendendo a questões sociais, utilizando o enfoque do grupo operativo, entrando em contato com questões institucionais. A partir desse momento, o Núcleo passou a reunir várias teorias como a Análise Institucional, a Esquizoanálise e outras, objetivando construir uma visão, uma leitura, uma proposta e uma ação mais abrangentes.

Um dos pressupostos teóricos do Núcleo são as propostas de Deleuze e Guattari a respeito da Esquizoanálise. 0 que é Esquizoanálise?

João Dias - A Esquizoanálise é uma forma de filosofia que se instituiu na França, na década de 1970, por meio de Gilles Deleuze e Félix Guattari, a qual propõe uma nova concepção das formas de pensar e existir do homem na contemporaneidade. Esquize quer dizer fragmento, e esta palavra denota exatamente a proposta dessa filosofia: fazer a análise das micropolíticas sociais, ultrapassando certos conceitos firmemente arraigados, como o de sujeito e o declasses sociais, em busca de uma compreensão mais adequada das novas formas de subjetividades contemporâneas. 
Qual é a importância da Esquizoanálise na sociedade contemporânea?

João Dias - As atuais formas de produção das subjetividades idéias, sentidos, significações, códigos sociais - não podem ser bem compreendidas se não atentarmos para suas novas configurações, ultrapassando certas dicotomias solidamente instaladas, como eu/outro, sujeito/objeto, indivíduo/sociedade, dentro/fora. Tais dicotomias dificultam a percepção das subjetividades nascentes que se produzem fora desses padrões binários. As novas formas de percepção encorajadas pela Esquizoanálise são fundamentais para que possam ser modificadas as relações sociais, na busca de novas formas de existir em sociedade.

Concretamente, a Esquizoanálise pode contribuir para melhorar as condições de trabalho em escolas, clínicas e noutros locais de aprendizagem?

Raquel Corrêa e Ângela Carneiro - Sim, e muito! A reflexão sobre a escola e outros locais de aprendizagem - suas relações, seus poderes - sejam eles governamentais ou não, sejam locais ou globais em seus programas de ação, pode ser muito melhorada e amplamente alterada. A concepção da subjetividade e de um mundo fragmentados e atravessados por códigos sociais que os determinam faz com que as relações estabelecidas ganhem flexibilidade e, conseqüentemente, sejam passíveis de modificações.

Que outras propostas teóricas são discutidas e trabalhadas pelo Núcleo? Em que circunstâncias são trabalhadas essas teorias (cursos, projetos sociais etc.) e como elas se articulam com a teoria esquizoanalítica?

Ângela Carneiro - Eu diria que a Análise Institucional é a prima mais velha da Esquizoanálise. Um de seus criadores foi Félix Guattari o qual cunhou o nome "Análise Institucional" para indicar o saber nascido após maio de 1968 na França. O grupalismo, com a noção de que o grupo não é somente a soma dos fenômenos que acontecem em seu interior, também é parente da Esquizoanálise, e considera o contexto exterior como o texto do grupo. Noutras palavras, essa teoria mostra que o grupo é atravessado por um exterior. Para a Análise Institucional, esse exterior são as instituições sociais - que atravessam e constituem o grupo - sendo essa concepção semelhante à da transversalidade presente na Esquizoanálise. Esse arsenal teórico é utilizado quando estamos atuando no campo, já que ele proporciona novas formas de compreensão e, conseqüentemente, novas atuações nas intervenções sociais que o NPPI realiza. 
- Núcleo oferece cursos regulares, possui uma biblioteca etc. Poderíamos dizer que ele é uma escola formal e também um centro de pesquisa e uma clínica? Essa seria uma estrutura arborescente, rizomática ou uma combinação de ambas?

João Dias - O NPPI oferece formação em Psicanálise, Esquizoanálise e Análise Institucional, além de preparar agentes para atuar em frentes de trabalho social. A pesquisa fomentada pelo Núcleo vem sempre acompanhada de ações concretas, tanto em escolas e organizações como junto à população carente e em situação de risco social. Nossos alunos e membros articulam os conhecimentos teóricos produzidos no NPPI com uma práxis social consistente. Todas essas formas de atuação se articulam entre si, fazendo incessantemente passagens de formas arborescentes - necessárias para organizar e estruturar as ações - para formas rizomáticas que sejam capazes de orientar nossas práticas a partir do novo, da diferença e do devir.

De sua fundação até hoje, quais foram as principais realizações do Núcleo?

Ângela Carneiro - O NPPI, desde sua fundação, sempre realizou diversos tipos de intervenções em organizações dos $1^{\circ}$ e $3^{\circ}$ setores - área governamental e área de organizações não governamentais que realizam atividades de interesse público. A partir de 1999, O NPPI realiza, de forma mais sistemática, principalmente no Aglomerado da Serra, diversos trabalhos com as pessoas e organizações locais. Mantemos diferentes tipos de atividades, tais como assessorias às escolas da rede pública no campo das análises institucionais, assessoria de agrupabilidade em associações comunitárias e organizações afins, atendimento numa clínica ampliada aos moradores do Aglomerado, criação e desenvolvimento de projetos de interesse social com esse público. Em todas essas atividades, nosso principal objetivo foi sempre a produção de novas subjetividades e a promoção da agrupabilidade nos coletivos sociais.

\section{Qual tem sido a utilização, por parte de educadores, terapeutas e outros atores sociais, do livro intitulado $\mathrm{Na}$ trama da rede social, recentemente publicado pelo Núcleo?}

Ângela Carneiro - Dentro do NPPI, ele é utilizado em aulas, principalmente no curso de Esquizoanálise e no Projeto Integração, onde contribui para a reflexão e a análise dos trabalhos realizados. Externamente, temos a prática de divulgação e doação desse livro a todos os projetos de interesse social dos quais o Núcleo participa: escolas, creches, centros culturais, universidades, entidades com finalidade social, conselhos etc. Os seminários, as palestras, 
aulas e intervenções que realizamos nesses locais são sempre acompanhados da oferta do livro, o que permite divulgar nossas experiências e as teorias com as quais essas ações são pensadas e realizadas.

\section{Quais são as principais metas do Núcleo, a curto e longo prazos?}

Ângela Carneiro e João Dias - Continuar formando psicanalistas, esquizoanalistas, analistas institucionais e agentes sociais que promovam mudanças no mundo - nas formas de as pessoas se relacionarem entre si, e também nas suas relações com o dinheiro, com a cidade, com as máquinas sociais, com a natureza e consigo mesmas. Contribuir para a construção de projetos e ações que, modificando as relações acima citadas, possam produzir mudanças nos coletivos sociais.

Belo Horizonte, 23 de março de 2008.

Contatos

Núcleo de Psicanálise e Práticas Institucionais Rua Dr. Alípio Goulart, 26 - Serra 30220-330 - Belo Horizonte - MG Telefone: (31) 3221-8471 Telefax: (31) 3264-5942

Site: http://nppibh.110mb.com e-mail: nucleopepi@hotmail.com 